\title{
PENGUJIAN SENSOR CAHAYA PHOTOTRANSISTOR DAN PHOTODIODE PADA PEMANTAU DENYUT JANTUNG DENGAN METODE PHOTOPLETHYSMOGRAPH REFLEKSI
}

\author{
Antonius Hendro Noviyanto \\ Program Studi Teknologi Elektromedis \\ Politeknik Mekatronika Sanata Dharma \\ Email: hendro@pmsd.ac.id
}

\begin{abstract}
ABSTRAK
Penelitian ini dilakukan karena banyaknya penyakit yang diakibatkan gangguan fungsi jantung dan pembuluh darah yang tidak terdeteksi secara dini. Pada makalah ini menyajikan pengujian dan pembuatan alat pemantau denyut jantung dengan sensor cahaya Phototransistor dan Photodiode sebagai penerima sinyal, sedangkan InfraRed dan Red LED digunakan sebagai sumber cahaya. Pengujian sensor ini dilakukan untuk mengetahui jenis sensor yang sesuai untuk menerima sinyal jantung dengan metode Photoplethysmograph refleksi. Pengujian dilakukan dengan membandingkan hasil baca dari beberapa sensor dengan sumber cahaya yang berbeda-beda. Sehingga dengan hasil pengujian yang didapatkan akan digunakan untuk membangun alat yang dapat memantau denyut jantung dan ditampilkan pada TFT LCD 32". Dari alat yang dibangun dihasilkan data yang memiliki selisih pengukuran sebesar 1 beat per minute (BPM).
\end{abstract}

Kata Kunci: photoplethysmograph; phototransistor; photodiode; denyut jantung.

\begin{abstract}
This research was conducted because of the many diseases caused by impaired heart and blood vessel function that were not detected early. So with this tool people will be easier to monitor the condition of the heart. In this paper, we present a test and manufacture of a heart rate monitor with a Phototransistor light sensor and a Photodiode as a signal receiver, while InfraRed and Red LED are used as light sources. This sensor testing is carried out to determine the type of sensor that is suitable for receiving heart signals by the reflection method of Photoplethysmograph. Testing is done by comparing the readings of several sensors with different light sources. So that the test results obtained will be used to build a tool that can monitor the heart rate and display on the TFT LCD 32". From the tools that are built, the data is generated which has a measurement difference of 1 beat per minute (BPM).
\end{abstract}

Keywords: photoplethysmograph; phototransistor; photodiode; heart rate.

\section{PENDAHULUAN}

Menurut data dari Pusat Data dan Informasi Kementrian Kesehatan RI[1], penyebab kematian nomor satu pada setiap tahunnya adalah disebabkan karena penyakit kardiovaskuler. Penyakit kardiovaskuler merupakan penyakit yang diakibatkan karena adanya ganguan fungsi jantung dan pembuluh darah. Pada umumnya, tahap awal dalam pemeriksaan secara medis dapat dilakukan dengan medical check up[2]. Dimana, pada medical check up tindakkan awal yang dilakukan adalah dengan melihat kondisi detak jantung dari seorang pasien.

Detak jantung pasien dapat diketahui dengan berbagai metode, yaitu: suara denyut jantung, mengukur denyut jantung (nadi), dan mengukur sinyal jantung dengan alat elektrokardiogram (EKG). Denyut nadi normal dari orang dewasa dikatakan normal jika berada dalam rentan 60 sampai 100 denyut/menit (beats/minute(bpm)[3]. Denyut nadi seseorang dikatakan tidak normal jika dalam rentan diatas 100 bpm (tachycardia) dan dibawah 60 bpm (bradycardia)[4].

Dampak dari seorang yang terkena tachycardia adalah jantung terlalu cepat berkontraksi dan darah yang dipompa untuk disalurkan ke seluruh tubuh hanya sedikit, sehingga fungsi jantung menjadi tidak normal. Seseorang dengan tachycardia dapat diketahui dengan tanda-tanda: sesak nafas, nadi cepat, nyeri dada, keringat dingin, dan tidak sadarkan diri .Tachycardia tidak menimbulkan suatu resiko yang komplikasi, namun jika kondisi tachycardia sudah parah dan sudah mengganggu fungsi normal jantung 
dapat mengakibatkan risiko stroke dan dapat pula menyebabkan serangan jantung mendadak yang dapat mengakibatkan kematian.

Pengukuran denyut jantung dapat dilakukan dengan metode photoplethysmography (PPG)[5], [6]. PPG merupakan suatu teknik yang dapat digunakan untuk mendeteksi terjadinya perubahan volume darah pada suatu jaringan tubuh, dengan cara menangkap sinyal yang dihasilkan dari sinar pemancar cahaya yang menembus jaringan kulit dan diterima oleh sensor penerima cahaya[7]. Pada metode tersebut terdapat komponen yang berfungsi sebagai pemancar sinar dan ada komponen yang berfungsi sebagai penerima sinar.

Berdasarkan penelitian yang sudah ada, pada hasil penelitian dari Budi Harsono[8] komponen yang digunakan adalah dengan sumber cahaya LED putih dan penerima cahaya dengan sensor photodiode. Pada penelitian tersebut menghasilkan alat pemantau laju detak jantung dengan hasil pembacaan yang dituliskan pada LCD 16x2. Pada penelitian Chitra Annisa Pratiwi[7], dihasilkan alat dengan sumber cahaya dari infra red dengan penerima cahaya photodiode. Hasil dari akuisisi data ditampilkan pada LCD 16x2. Pada penelitian Marti Widya Sari[9], dihasilkan alat dengan menggunakan pulse sensor dari finger test. Hasil dari pembacaan ditampilkan pada monitor laptop.

Penelitian ini akan membahas mengenai komponen sensor optik dan sumber cahaya yang tepat untuk membangun suatu alat pemantau denyut jantung. Sehingga akan didapatkan alat pemantau denyut jantung yang dapat digunakan dan sinyal hasil pemantauan dapat dilihat pada TFT LCD 32" yang terdapat pada alat.

\section{BAHAN DAN CARA}

Pada penelitian ini menggunakan dua jenis sensor optik, yaitu photodiode dan photoransistor dan dua jenis pemancar cahaya, yaitu Red LED dan InfraRed. Photodiode dan phototransistor merupakan jenis sensor yang dapat menerima cahaya, baik cahaya tampak ataupun cahaya yang tak tampak. Red LED merupakan komponen yang dapat memancarkan cahaya tampak berwarna merah, sedangkan InfraRed merupakan komponen yang dapat memancarkan cahaya tak tampak.

Proses pengambilan data menggunakan konfigurasi refleksi, yaitu: antara pemancar dan penerima dipasang secara. Pada konfigurasi refleksi pemancar memancarkan gelombang cahaya dan dipantulkan ke penerima. Besar intensitas cahaya yang diterima oleh penerima dipengaruhi oleh volume darah yang mengalir pada suatu organ. Sinyal yang dihasilkan dari sensor memiliki banyak noise dan sangat kecil nilainya. Agar dapat diproses lebih lanjut, sinyal harus dikuatkan dan difilter untuk menghilangkan noise yang ada pada sinyal tersebut. Penguatan sinyal dapat dilakukan dengan berbagai macam cara, salah satunya adalah dengan menggunakan IC Op-Amp. Rangkaian pengkondisi sinyal yang digunakan menggunakan rangkaian yang sudah pernah dikembangkan[10] seperti yang ditunjukkan pada gambar 1, dengan melakukan sedikit perubahan pada rangkaian input dan IC yang digunakan. Pada rangkaian yang digunakan terdapat rangkaian filter lolos rendah dengan frekuensi cut-off 2,34 Hz[10]. Penguatan sinyal yang digunakan pada rangkaian pengkondisi sinyal ini adalah dengan menggunakan penguatan sebesar 10.201 kali.

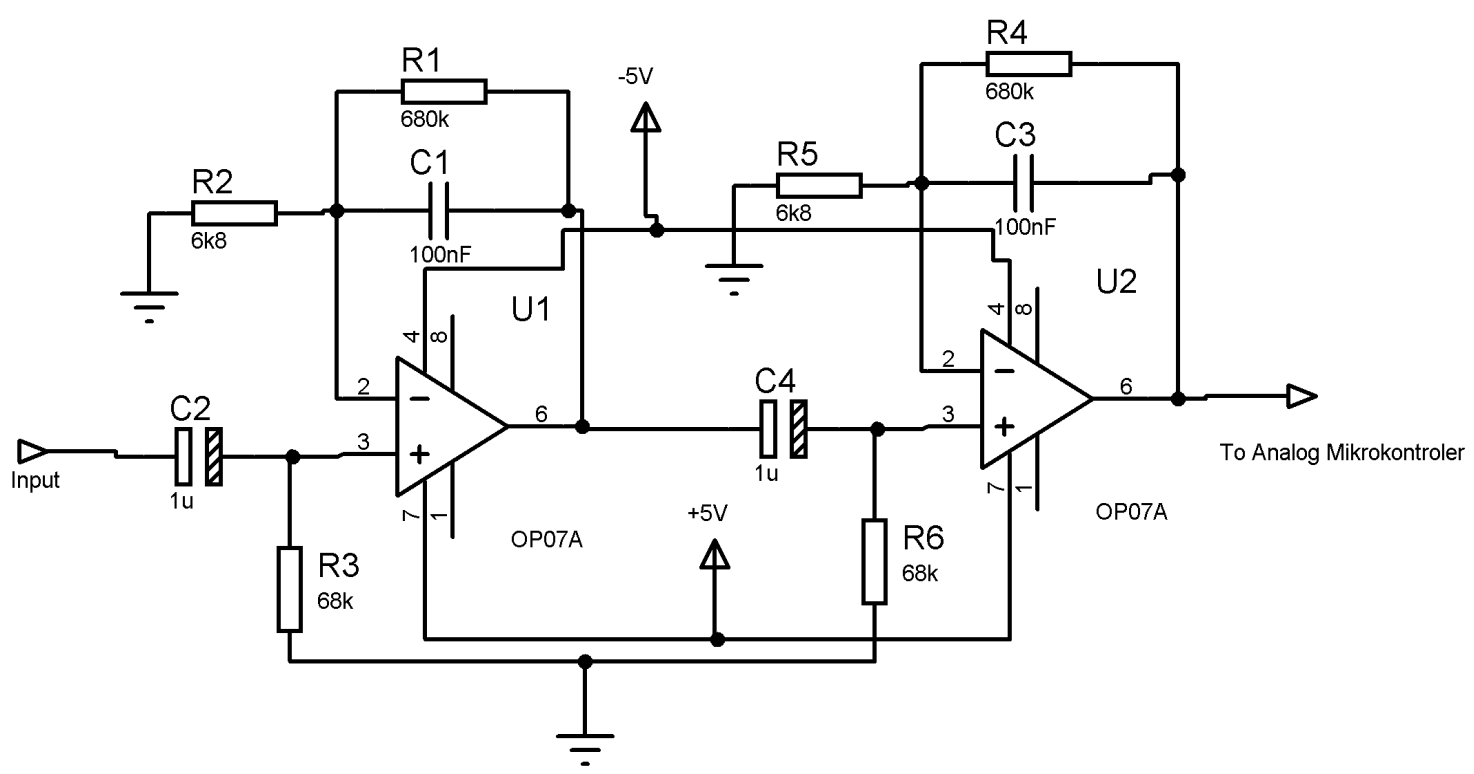

Gambar 1. Rangkaian Pengkondisi Sinyal 
Setelah sinyal yang diharapkan telah didapat, sinyal dapat diproses lebih lanjut sesuai dengan yang dibutuhkan. Pemrosesan sinyal dilakukan dengan menggunakan mikrokontroler dan ditampilkan pada TFT LCD 32".

\section{HASIL DAN PEMBAHASAN}

Pada penelitian ini dilakukan pengambilan data-data sensor sebagai berikut:

\subsection{Red LED - Photodiode}

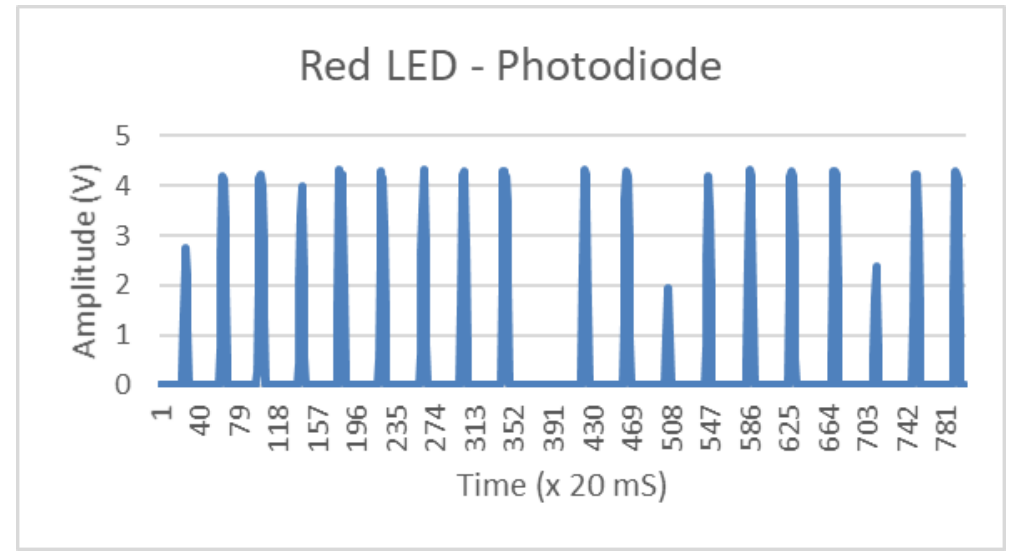

Gambar 2. Grafik Pengujian Red LED-Photodiode

Pada gambar 2 menunjukkan hasil pengujian RED LED dengan Photodiode. Pada hasil tersebut menunjukkan adanya sinyal yang hilang saat dilakukan pengujian. Tegangan keluaran dari pengkondisi sinyal sudah cukup besar yaitu 4 volt.

\subsection{Red LED - Phototransistor}

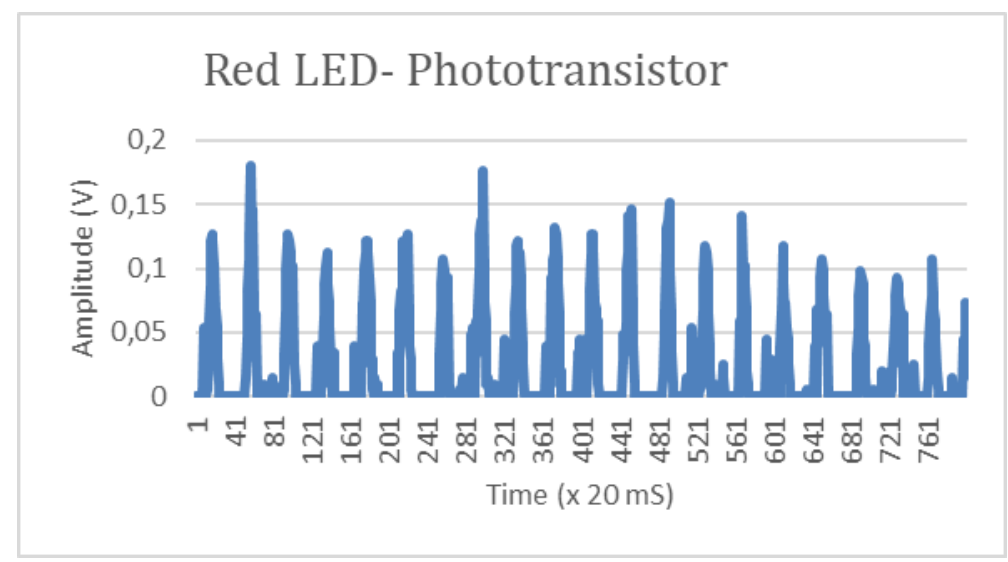

Gambar 3. Grafik Pengujian Red LED-Phototransistor

Pada gambar 3 menunjukkan hasil pengujian RED LED dengan Phototransistor. Pada hasil tersebut menunjukkan adanya sinyal masih terdapat noise dan tegangan yang dihasilkan sangat kecil. 


\subsection{Infra Red-Photodiode}

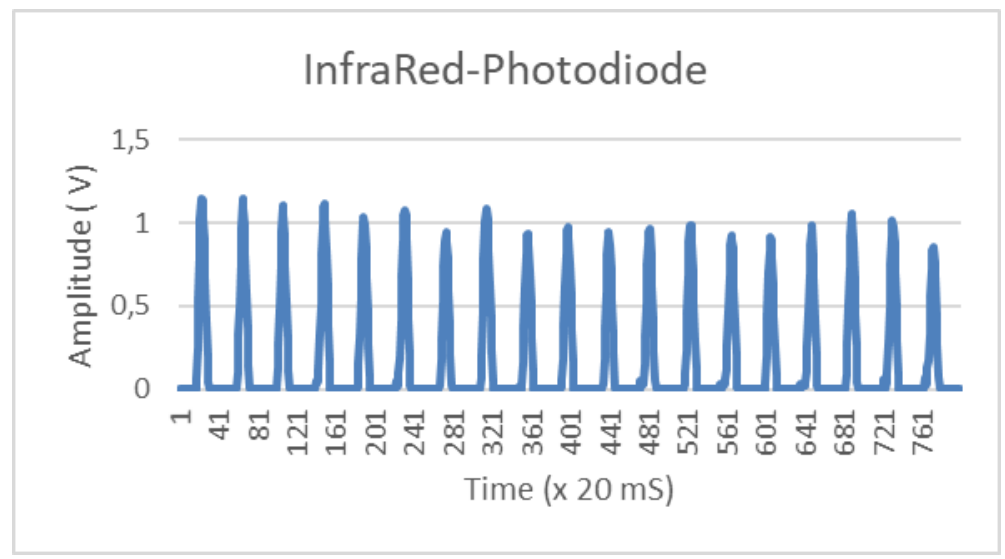

Gambar 4. Grafik Pengujian Infra Red-Photodiode

Pada gambar 4 menunjukkan hasil pengujian Infra Red dengan Photodiode. Pada hasil tersebut menunjukkan hasil yang bagus dan noise dapat dihilangkan secara maksimal.

\subsection{Infra Red-Phototransistor}

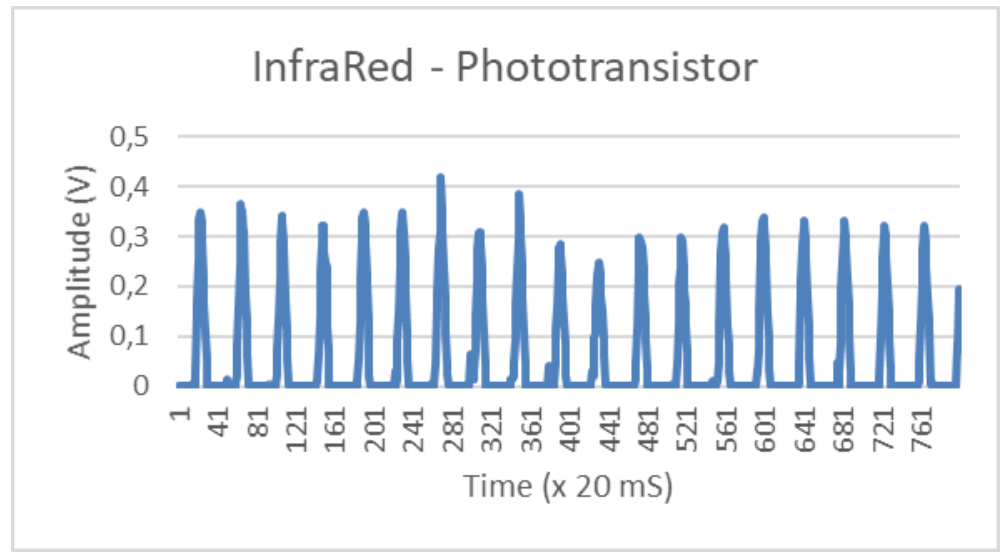

Gambar 5. Grafik Pengujian Infra Red-Phototransistor

Pada gambar 5 menunjukkan hasil pengujian Infra Red dengan Phototransistor. Pada hasil tersebut menunjukkan hasil yang menunjukkan masih adanya noise dan tegangan keluaran yang dihasilkan masih dalam skala yang kecil.

Berdasarkan dari hasil pengujian yang telah dilakukan, maka dilakukan pembuatan alat pemantu denyut jantung dengan menggunakan sensor Photodiode dengan sumber cahaya dari infra red. Pada gambar 6 merupakan alat pemantau denyut jantung. Pada alat terdiri dari unit input yang tersusun dari sensor Photodiode dengan sumber cahaya dari Infra Red, unit pengkondisi sinyal yang tersusun atas rangkaian penguat dan filter, unit pemrosesan yang terdiri atas mikrokontroler, dan unit output/display yang terdiri dari LCD penampil. 


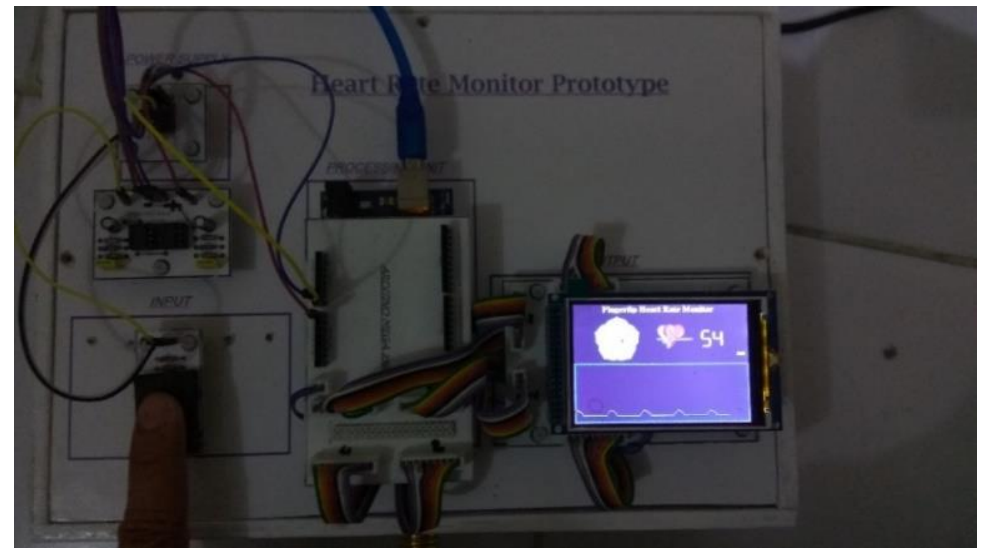

Gambar 6. Alat Pemantau Denyut Jantung

Pengujian deterktor denyut jantung dilakukan sebanyak 5 kali dengan data sebagai berikut ditunjukkan pada tabel 1. Pengujian dilakukan dengan membandingkan hasil pembacaan alat yang dibuat dengan alat fingertip Oximeter.

Tabel 1. Data pengujian detektor denyut jantung

\begin{tabular}{ccc}
\hline No & Detektor Denyut Jantung (BPM) & $\begin{array}{c}\text { Fingertip Oximeter } \\
(\text { BPM })\end{array}$ \\
\hline 1 & 66 & 65 \\
2 & 70 & 70 \\
3 & 72 & 72 \\
4 & 76 & 75 \\
5 & 80 & 81 \\
\hline
\end{tabular}

Pada pengujian pertama, keempat, dan kelima didapatkan selisih pengukuran sebesar 1, sedangkan pada pengujian kedua dan ketiga didapatkan hasil yang sama. Berdasarkan dari data tersebut didapatkan selisih perhitungan 1 BPM, dengan nilai kesalahan sebesar $1,25 \%$.

Secara umum, data yang dihasilkan dari pembacaan sensor yang digunakan sudah menunjukkan terbacanya sinyal dari detak jantung. Namun untuk sensor Red LED - Photodiode dan Red LED Phototransistor memiliki hasil pengujian yang kurang bagus, dimana hasil menunjukkan adanya data yang hilang dan masih terdapat banyak noise yang dihasilkan.

Berdasarkan dari hasil pengambilan data yang telah dilakukan, konfigurasi sensor yang secara umum baik digunakan dengan rangkaian pengkondisi sinyal yang dipilih adalah Infra Red - Photodiode dan Infra Red - Phototransistor. Pada hasil pengambilan data tersebut menunjukkan terbacanya semua sinyal detak jantung (tidak ada sinyal yang tidak terbaca) dan noise yang dihasilkan kecil. Berdasarkan data hasil pengujian yang telah didapatkan, dihasilkan alat pemantau detak jantung dengan penampil TFT LCD 32". Dengan tamilan LCD ini dapat dilihat sinyal dari detak jantung dan jumlah detak jantung dalam satuan BPM.

\section{KESIMPULAN}

Penelitian ini menyajikan hasil pengujian sensor cahaya phototransisor dan photodiode dengan sumber cahaya red LED dan infra red yang digunakan pada alat pemantau denyut jantung. Konfigurasi sensor yang digunakan adalah sensor infra red dengan photodiode. Sinyal yang didapatkan dan jumlah denyut jantung dalam per menit dapat dilihat pada monitor TFT LCD 32" dengan nilai kesalahan sebesar $1,25 \%$.

\section{DAFTAR PUSTAKA}

[1] Kemenkes RI, "Situasi kesehatan jantung," Pus. data dan Inf. Kementeri. Kesehat. RI, p. 3, 2014.

[2] Khasanah Uswatun, "Berdasarkan Usia Menggunakan Pulse Sensor Berbasis Arduino Uno," J. Elektron. Pendidik. Tek. Elektron., vol. 5, pp. 1-7, 2016.

[3] E. Laskowski, "What's a normal resting heart rate?" [Online]. Available: http://www.mayoclinic.com/health/heart-rate/AN01906. 
[4] D. A. S, F. Arisgraha, and R. Apsari, "Bradycardia and Tachycardia Detection System With Artificial Neural Network Method," Indones. J. Trop. Infect. Dis., vol. 3, no. 2, p. 86, 2017.

[5] J. Allen, "Photoplethysmography and its application in clinical physiological measurement," Physiol. Meas., vol. 28, no. 3, pp. 1-39, 2007.

[6] N. Saquib, M. T. I. Papon, I. Ahmad, and A. Rahman, "Measurement of heart rate using photoplethysmography,” Proc. 2015 Int. Conf. Netw. Syst. Secur. NSysS 2015, 2015.

[7] C. A. Pratiwi, P. Madona, and P. Wijaya, "Akuisisi Data Sinyal Photoplethysmograph (PPG) Menggunakan Photodioda," J. Politek. Caltex Riau, vol. 2, no. 2, pp. 33-42, 2016.

[8] B. Harsono, "Rancang Bangun Alat Pemantau Detak Jantung Saat Latihan Fisik," J. Tek. dan Ilmu Komput., vol. 1, no. 4, pp. 338-346, 2012.

[9] M. W. Sari and S. Wardani, "Rancang Bangun Aplikasi Monitoring Detak Jantung Melalui Finger Test Berbasis Arduino,” J. EKSIS, vol. 9, pp. 105-112, 2016.

[10] "Embedded Lab." [Online]. Available: http://embedded-lab.com/blog/heart-rate-measurement-fromfingertip/. 